\title{
Influence of the Blending Method and Poly(methyl methacrylate) Tacticity in Its Miscibility with Poly(hydroxy ether of bisphenol A, phenoxy)
}

\author{
Mireia Alberdi, Enrique EsPi, ${ }^{\dagger}$ Maria J. Fernandez-Berridi, \\ and Juan J. IRUIN* \\ Departamento de Ciencia y Tecnologia de Polimeros, \\ Universidad del Pais Vasco, Facultad de Quimica, \\ P.O. Box 1072, 20080 San Sebastian (Spain)
}

(Received January 7, 1994)

\begin{abstract}
Blends of poly(hydroxy ether of bisphenol-A) (phenoxy) and poly(methyl methacrylate) exhibit a different phase behaviour depending on the blending method. Additionally, both polymers present similar glass transition temperatures complicating the study of the phase behaviour by classical DSC methods. The problem has been resolved by using different experimental techniques (enthalpy relaxation, DMTA, CP-MAS NMR) which have confirmed the intrinsic miscibility of this blend. The influence of the poly(methyl methacrylate) tacticity in the miscibility of the blends has also been studied.

KEY WORDS Miscibility / Polymer Blends / Thermal Properties / Relaxation Enthalpy / Tacticity / CP-MAS NMR / DMTA / DSC /
\end{abstract}

The formation of miscible blends of two high molecular weight polymers is not a common phenomenon. However, miscibility can be achieved if there are some specific intermolecular interactions between the two components, such as hydrogen-bonding, ion-dipole, dipole-dipole, $\pi$-bonding, or charge transfer interactions.

The present study mainly concerns the miscibility behavior of phenoxy (PH) and poly(methyl methacrylate) (PMMA) and how this behavior depends on the blending method and the tacticity of PMMA. The phenoxy resin (PH), a polymer composed of bisphenol A and epichlorohydrin, has repeatedly been proved to be miscible with poly(ethylene oxide), ${ }^{1,2}$ poly(vinyl methyl ether), ${ }^{3}$ polyesters, ${ }^{4,5}$ polysulphones, ${ }^{6}$ polyamides, ${ }^{7}$ etc. It contains a secondary hydroxyl group in the main chain capable to self-associate by hydroxyl-hydroxyl interactions like simple alcohols or phenols. A second type of self-association results from the interaction between this hydroxyl group and the ether group attached to the aromatic ring. The other component of the blend, PMMA,

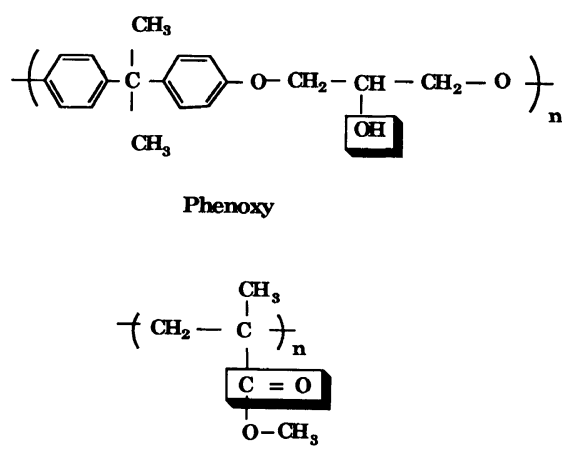

PMMA

* To whom correspondence should be addressed.

† Present address: Repsol Petroleo S.A., Research Center, P.O. Box 17044, 28080 Madrid, Spain. 
has a carbonyl group which can form, in principle, hydrogen bonding with the hydroxyl group of the PH resin.

PH and PMMA blend miscibility has been previously reported. ${ }^{8,9}$ However, when both polymers are melt-mixed, the physical appearance of the blends depends markedly on the operating conditions, ${ }^{8}$ indicating some level of difficulty in attaining the adequate degree of dispersion necessary to miscibility. On the other side, cloudy blend films are obtained by casting from the practical totality of common solvents. However, miscible blends seem to be formed from a solution-precipitation method. One of the objectives of this work is to clarify such behaviour.

An additional difficulty in studying this particular blend arises from the fact that pure polymers, PH and PMMA, have similar glass transition temperatures. Calorimetric measurements, using the glass transition temperature $\left(T_{\mathrm{g}}\right)$ as a macroscopic test of miscibility, become invalid to establish the phase behaviour of this system. In similar cases, the enthalpy recovery phenomenon in physically aged glassy blends has been reported ${ }^{10}$ to be a useful procedure to determine polymer-polymer miscibility. Enthalpy relaxation results can be confirmed by using Dynamic Mechanical Thermal Analysis (DMTA), more sensitive than DSC in detecting second order transitions.

The study has been completed by using magic angle cross-polarization ${ }^{13} \mathrm{C}$ NMR, a valuable tool to measure the limits of miscibility or miscibility range. ${ }^{11-15}$ The CP-MAS ${ }^{13} \mathrm{C} \mathrm{NMR}$ in solid state gives information about a molecule or functional group in a dimensional range between few armstrongs and $10 \mathrm{~nm}$. The spatial range observed by other techniques such as DSC or DMTA falls around 20 or $30 \mathrm{~nm}$ as far as they measure chain dynamics involving 20 or 30 monomeric units. Light transmission experiments based on refractive index differences only appreciate domain sizes in a range of $100 \mathrm{~nm}$.

One of the components of the mixture,
PMMA, presents tacticity as a consequence of its asymmetric quaternary carbon. Many systems with different phase behaviour depending on the tacticity of the constituents have been reported in the literature. ${ }^{16-18}$ Lemieux and Prud'homme ${ }^{16}$ showed different phase diagrams for poly(vinyl chloride) (PVC) blended with isotactic and syndiotactic PMMA. They explained this behaviour on the basis of the different polymer chain flexibility and its relation with the interaction parameter and the polymer free volume. For being the isotactic polymer chain conformation more flexible than the atactic one, lower LCST diagrams were obtained. With the aim of verifying if our system could also have some kind of tacticity dependence, two predominantly isotactic PMMA and syndiotactic PMMA were used.

\section{EXPERIMENTAL}

\section{Materials}

Two different Phenoxy (PH) resins were used: a commercially available product of Union Carbide (PKHH) and a very low molecular weight $\mathrm{PH}$ resin synthesized in our laboratory. We also used different molecular weight atactic polymethyl methacrylates (PMMA): a commercial sample of Diakon CMH 454/L (ICI) and three narrow standards of a-PMMA with low, medium and high molecular weight. These standards and two samples of isotactic and syndiotactic PMMA were obtained from Polymer Laboratories. Commercial samples were purified by precipitation from tetrahydrofuran (THF) solutions in an excess of $n$-hexane and dried under vacuum for at least $48 \mathrm{~h}$. Molecular weights were determined at $25^{\circ} \mathrm{C}$ by Size Exclusion Chromatography (SEC-GPC) in a Waters 150-C ALC/GPC Chromatograph equipped with a linear column PLgel (Polymer Labs.), using THF as eluent. Values of $M_{w}$ and $M_{n}$ were calculated relative to polystyrene (PS) standards. $T_{\mathrm{g}}$ values and molecular weights are shown in Table I. The Mark-Houwink $\boldsymbol{K}$ and $\boldsymbol{a}$ constants used for 
Table I. Glass transition temperatures and molecular weights of the polymers

\begin{tabular}{|c|c|c|c|}
\hline Sample & $\frac{T_{\mathrm{g}}}{{ }^{\circ} \mathrm{C}}$ & $M_{n}$ & $M_{w}$ \\
\hline PH (Ucar) & 95 & 18000 & 50800 \\
\hline PH II & 88 & 2800 & 9300 \\
\hline PMMA & 110 & 55000 & 120000 \\
\hline PMMA II & 120 & 42000 & 502600 \\
\hline PMMA III & 116 & 95500 & 105000 \\
\hline PMMA IV & 92 & 7800 & 9900 \\
\hline s-PMMA & 115 & 29000 & 34000 \\
\hline i-PMMA & 50 & 4750 & 19000 \\
\hline PMMA (fr. $)^{a}$ & - & 129800 & 460000 \\
\hline
\end{tabular}

a High molecular weight fraction from fractionation.

$\mathrm{PMMA}^{19}$ and $\mathrm{PH}^{20}$ resin have been previously reported.

Tacticities of the PMMA samples were determined for the spectra registered on a ${ }^{13} \mathrm{C}$ Varian VXR-300 NMR spectrometer (75 $\mathrm{MHz}$ ) from polymer solutions ( $20 \%$ by weight) in deuterated chloroform at $20^{\circ} \mathrm{C}$ using TMS as internal reference. The percentage of isotactic and syndiotactic triads for i-PMMA and s-PMMA are $95.3 \%$ and $89.7 \%$ respectively.

\section{Preparation of Blends}

Blends of PH and PMMA were prepared by three different ways: casting, coprecipitation and melt-mixing. Solution blending was performed by casting $\sim 1 \mathrm{wt} \%$ mixed solution onto a glass plate. The films were dried under vacuum at room temperature. To remove last traces of solvent the films were kept at $50^{\circ} \mathrm{C}$ for $48 \mathrm{~h}$ under vacuum. Precipitated blends were prepared using THF as the solvent and $n$-hexane as the non-solvent, the final composition being tested by ${ }^{1} \mathrm{H}$ NMR $(300 \mathrm{MHz}$, Varian). Melt mixing was carried out in a Mini Max Molder (Custom Scientific Instruments, CD-183MMX model), a mini extruder which needs very low amount of sample. This characteristic makes it very interesting and useful for scientific purposes where great amounts of the components are not usually available. The Mini Max Molder is equipped with a temperature controller and a variable speed mixing rotor.

\section{Differential Scanning Calorimetry (DSC)}

Thermal analysis was performed with a Perkin Elmer DSC-2C differential scanning calorimeter. The onset of the specific heat jump was taken as the glass transition temperature, $T_{\mathrm{g}}$. Samples for aging were kept at a temperature $T_{0}>T_{\mathrm{g}}$ for $10 \mathrm{~min}$ to erase previous thermal history. The process was followed by a rapid cooling to the aging temperature $\left(T_{\mathrm{a}}\right)$ where the samples were maintained during a variable period of time $\left(t_{\mathrm{a}}\right)$. After $t_{\mathrm{a}}$ the samples were rapidly cooled to $47^{\circ} \mathrm{C}$ and a standard scan at $20^{\circ} \mathrm{C} \mathrm{min}^{-1}$ from 47 to $147^{\circ} \mathrm{C}$ was taken. A second scan in identical conditions was immediately recorded. Two experimental aging temperatures, 82 and $86^{\circ} \mathrm{C}$ were tested, aging times ranged from 4 to $117 \mathrm{~h}$. At the $T_{0}$ temperature neither degradation nor homogenization of phase separated samples should have occurred.

\section{Dynamic Mechanical Thermal Analysis (DMTA)}

A Polymer Laboratories DMTA machine was used. From blends prepared by each one of the three methods above mentioned, $0.8 \mathrm{~mm}$ thick DMTA specimens were obtained by pressing the mixture at 10 tons and $180^{\circ} \mathrm{C}$ between hot plates. DMTA scans were carried out at a constant heating rate of $4^{\circ} \mathrm{C} \mathrm{min}^{-1}$ in a temperature range from $30^{\circ} \mathrm{C}$ until the sample became too soft to be tested. Oscillatory frequency was $1 \mathrm{~Hz}$.

\section{Solid-State ${ }^{13} C$ NMR}

All solid-state NMR experiments were performed in a Varian VXR-300 spectrometer equipped with a magic angle spinning accessory. Pure $\mathrm{PH}$ and precipitated $\mathrm{PH} / \mathrm{PMMA}$ blend samples were packed in a sapphire rotor. Spinning rates were generally $3 \mathrm{kHz}$. For the removal of the spinning side bands, spinning 
rate adjustments were made when necessary. A $90^{\circ}$ pulse width of $5 \mu \mathrm{s}$ was employed in conjunction with 256 fid signal accumulations. Adamantane was used to adjust the field homogeneity. Proton spin-lattice relaxation times (in the rotating frame) were measured via carbon signal intensities using a $90_{\mathrm{x}}^{\circ}-\tau$-spin lock pulse sequence prior to cross-polarization. Data acquisition was performed via ${ }^{1} \mathrm{H}$ decoupling, and delay times $(\tau)$ ranged from 0.5 to $45 \mathrm{~ms}$. All spectra were obtained at room temperature.

\section{Film Clarity Investigations}

Clarity of the films was monitorized with a programmable hot stage. In some cases, samples were prepared by casting directly on a glass plate. In the case of blends prepared by precipitation they were pressed under 10 tons at $180^{\circ} \mathrm{C}$ for $5 \mathrm{~min}$ after which clear films were obtained.

\section{RESULTS AND DISCUSSION}

The preparation of miscible mixtures of $\mathrm{PH}$ and PMMA polymers presents some technical difficulties. In preparing blends by melt-mixing, clear extruded samples were obtained at $205^{\circ} \mathrm{C}$ and a rotor rate of $85 \mathrm{rpm}$, the extruding time being $10 \mathrm{~min}$. Melt-mixing conditions are limited from one side by the high viscosity of the components at low extruding temperatures and the degradation problems of PMMA on the other. A more detailed study of PH/PMMA melt-mixed blends has been done by Erro and coworker. ${ }^{8}$ From the same paper we can conclude that, at the previously indicated melting conditions, the sample has not suffered any degradative process. Despite meltmixed blends were transparent, cast samples from THF, chloroform, dioxane or dimethyl formamide (DMF) were opaque in all cases. Opacity did not disappear after keeping the samples of high molecular weight polymers several hours at $160^{\circ} \mathrm{C}$. This temperature is a compromise between the glass transition temperatures $\left(T_{\mathrm{g}}\right)$ of the components and the PMMA degradation temperature. Blends were also prepared by coprecipitating solutions of both components in a common solvent. When these blends were dried and hot-pressed, transparent films were obtained in all cases.

\section{Relaxation Enthalpy and Miscibility}

With the aim of establishing the miscibility of the system formed by PH and PMMA by a calorimetric technique, and bearing in mind that they have similar $T_{\mathrm{g}}$ values, we appealed to physical aging and subsequent entalphy relaxation phenomena. This type of process is usually carried out at an aging temperature 20 or $30^{\circ} \mathrm{C}$ below $T_{\mathrm{g}}$ and an adequate aging time.

Enthalpy relaxation in amorphous polymers appears when samples are quenched from the melting state to a non equilibrium glassy state. Keeping the samples at a temperature below $T_{\mathrm{g}}$ for a period of time, some properties such as enthalpy and volume tend to their equilibrium values at that particular temperature. Each polymer has its own specific aging behaviour, manifested in the position and magnitude of the enthalpy recovery peak. This fact can be used to determine polymer-polymer miscibility when the $T_{\mathrm{g}}$ 's of the components are very close to each other. This has already been demonstrated by various authors. ${ }^{10,21-23}$

A short introduction of the phenomenon of the glass forming will be given. The enthalpy relaxation kinetics are highly non linear and some phenomenological models describing their evolution have been proposed. ${ }^{24-28} \mathrm{~A}$ number of authors have studied the phenomenon experimentally ${ }^{29-39}$ and the equation which best describes the enthalpy variation with aging time is ${ }^{29}$ :

$$
\Delta H=\Delta H_{\infty}\left[1-\Phi\left(t_{\mathrm{a}}\right)\right]
$$

where

$$
\Phi\left(t_{\mathrm{a}}\right)=\exp \left[-\left(\frac{t_{\mathrm{a}}}{t_{\mathrm{c}}}\right)^{\beta}\right]
$$

is the well-known Williams-Watt function 
often used to describe relaxation behaviours in polymer systems. $\Delta H_{\infty}$ is the enthalpy difference at $T_{\mathrm{a}}$ between the enthalpy in the equilibrium and that in the starting state. $\Delta H$ is the same difference at the same temperature between the enthalpy in the passed time $\left(t_{\mathrm{a}}\right)$ and the starting value. $\beta$ is a measure of the width of the relaxation spectrum, its value ranging from 0 to 1 . Sub- $T_{\mathrm{g}}$ peaks are a consequence of the memory effects which, in turn, imply that the value of $\beta$ in eq 2 has to be smaller than 1 . This memory effect describes the observation that the relaxation in a particular state depends not only on this state but also on the way it was reached. When $\beta=1$ the relaxation time is unique and the more its value approaches zero the broader the peak becomes.

$t_{\mathrm{c}}$ is an Arrhenius type aging characteristic time introduced by Yoshida and coworkers ${ }^{30}$ :

$$
t_{\mathrm{c}}=A \exp \left(\frac{E}{R T}\right)
$$

or, in a more complicated form, by Narayanaswamy $^{40}$ :

$$
t_{\mathrm{c}}=A \exp \left(\frac{E}{R T}+\frac{(1-x) E}{R T_{\mathrm{f}}}\right)
$$

where $x$ is a non-linearity dependent parameter introduced by Moyhigan and coworkers, ${ }^{38} E$ is the activation energy and $R$ the ideal gas constant. $T_{\mathrm{f}}$ was introduced by Tool $^{41}$ and defined as the temperature at which the observed property would have the equilibrium value.

The lost enthalpy evolution of the phenoxy resin with the aging time when $\mathrm{PH}$ is physically aged at various temperatures has been studied. From the $C_{\mathrm{p}}$ versus temperature thermogram the lost enthalpy value can be calculated at each aging time and aging temperature, $\Delta H\left(t_{\mathrm{a}}, T_{\mathrm{a}}\right)$. Indium melting enthalpy was taken as a reference. A series of aging temperatures was used: $92,87,82,77$, and $72^{\circ} \mathrm{C}(6,11,16$, 21 , and $26^{\circ} \mathrm{C}$ below the $\mathrm{PH}$ resin transition temperature). Aging times decreased as $T_{\mathrm{a}}$ approaches $T_{\mathrm{g}}$, the polymer relaxed faster the closer both temperatures were.

Figure 1 shows the $\Delta H\left(t_{\mathrm{a}}, T_{\mathrm{a}}\right)$ versus aging time plot. By using a modified linear regression curve-fitting analysis according to equation 1 , $\Delta H_{\infty}\left(T_{\mathrm{a}}\right), t_{\mathrm{c}}$, and $\beta$ parameters can be determined from these data (see Table II). The evolution of the curve with temperature is similar to that proposed by Cowie and Ferguson ${ }^{29}$ and does not approach to the linear variation supposed by Yoshida and Kobayashi. ${ }^{30}$ The result was not surprising. The contrary would mean that melted polymer and solid polymer in equilibrium should have a temperature independent specific heat $\left(C_{\mathrm{p}}\right)$.

In this work, an Arrhenius type temperature dependence of $t_{\mathrm{c}}$ seems to work well. When $\ln t_{\mathrm{c}}$ is plotted versus $T_{\mathrm{g}}-T_{\mathrm{a}}$ linear relationships are obtained for phenoxy resin as well as

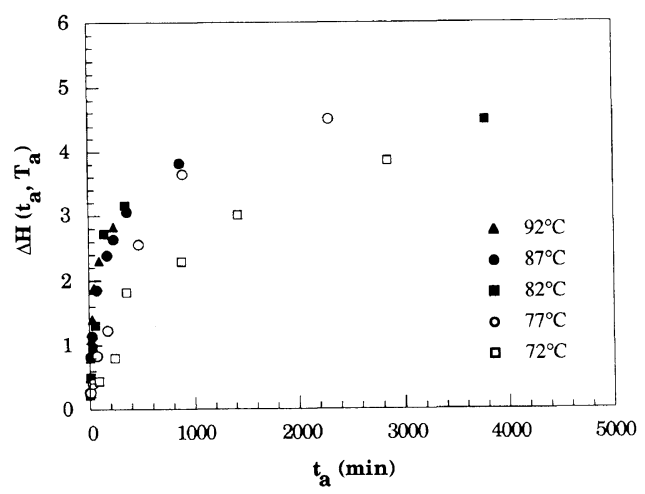

Figure 1. The enthalpy lost by $\mathrm{PH}$ resin at different aging temperatures.

Table II. Characteristic parameters of the phenoxy

\begin{tabular}{|c|c|c|c|c|c|}
\hline$T_{\mathrm{g}}$ & \multirow{2}{*}{$T_{\mathrm{g}}-T_{\mathrm{a}}$} & \multirow{2}{*}{$1 / T_{\mathrm{a}} \times 10^{3}$} & \multirow{2}{*}{$\frac{H_{\infty}}{\mathrm{Jg}^{-1}}$} & \multirow{2}{*}{$\frac{t_{\mathrm{c}}}{\min }$} & \multirow{2}{*}{$\beta$} \\
\hline $\mathrm{K}$ & & & & & \\
\hline 365 & 6 & 2.74 & 3.31 & 74.18 & 0.57 \\
\hline 360 & 11 & 2.78 & 4.18 & 213.8 & 0.59 \\
\hline 355 & 16 & 2.82 & 4.72 & 418.8 & 0.57 \\
\hline 350 & 21 & 2.86 & 5.07 & 786.9 & 0.72 \\
\hline 345 & 26 & 2.90 & 5.13 & 1703 & 0.79 \\
\hline
\end{tabular}
enthalpy relaxation behavior 

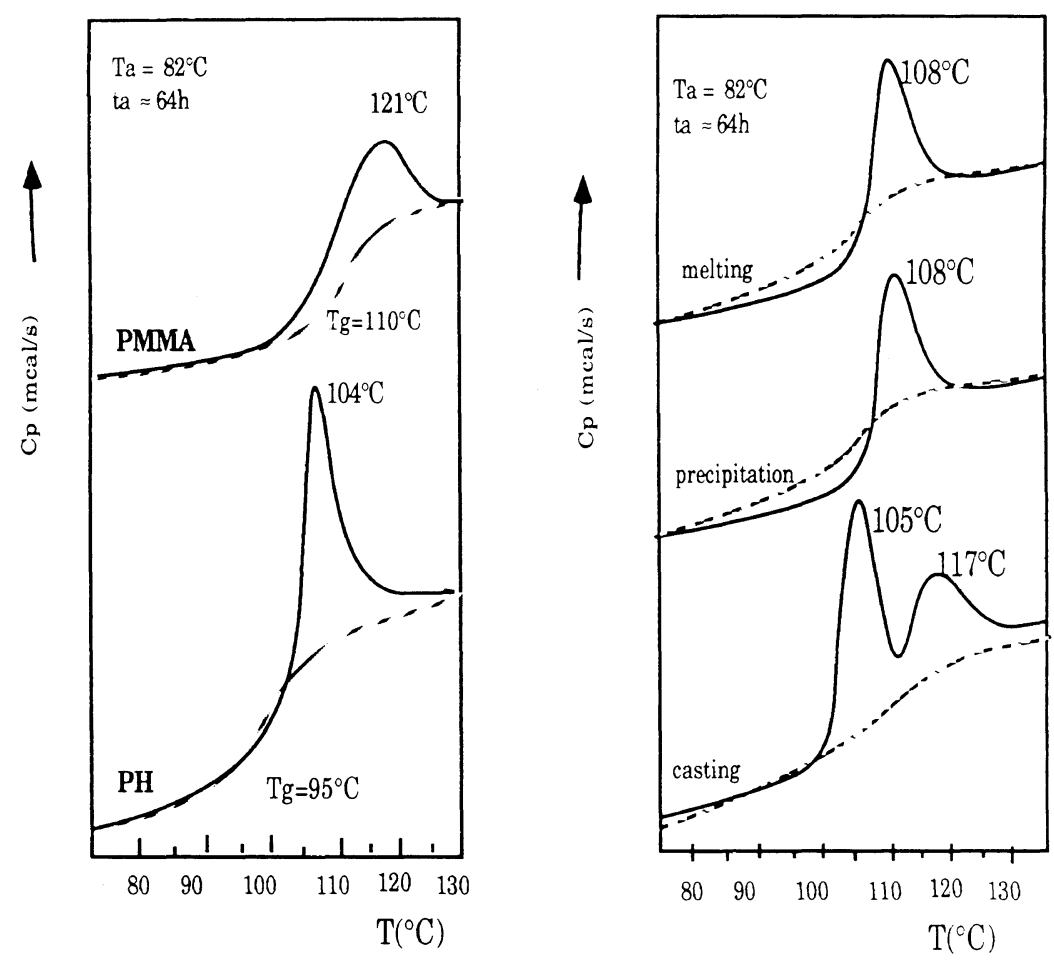

Figure 2. Thermograms of pure $\mathrm{PH}$ and PMMA polymers and PH/PMMA 50:50 wt. blends obtained by casting, precipitation and melt-mixing after aging at $82^{\circ} \mathrm{C}$ for $\sim 64 \mathrm{~h}(-)$; second scan (-----).

for PMMA. ${ }^{30}$ On the other hand, from the slope of $\ln t_{\mathrm{c}}$ versus the reciprocal of temperature plot, activation energy values can be calculated. The value for phenoxy resin is 159 $\mathrm{kJ} \mathrm{mol}^{-1}$, smaller than those obtained for poly(methacrylate)s by Yoshida and Kobayashi, ${ }^{30}$ which ranged from 300 to $400 \mathrm{~kJ} \mathrm{~mol}^{-1}$.

Once the relaxation processes are well characterized, we can proceed with the investigation of the miscibility of the blends prepared by different methods. The selected temperature was 82,13 , and $28^{\circ} \mathrm{C}$ below the glass transition temperatures of phenoxy and PMMA, respectively. After annealing the samples prepared by the three methods at this temperature and after the subsequent DSC scan, enthalpy recovery peaks were obtained, as shown in Figure 2. PH/PMMA blend composition was $50: 50 \mathrm{wt}$ in all cases.

The blend prepared by casting resulted in two well-defined peaks at a given aging time and temperature, the immiscibility of the blend being so confirmed. However, blends prepared by melt-mixing or coprecipitation from a dilute solution showed a single recovery peak, indicative of miscibility. The dashed lines in the figure represent the second scan taken after erasing the physical aging.

\section{Dynamic Mechanical Analysis}

After proving the miscibility of our pair, we decided to use the DMTA technique to corroborate the results. Figure 3 shows the $\tan \delta$ versus temperature plot of a DMTA scan of the pure PH and PMMA and those of the $50: 50 \mathrm{wt}$ blends prepared by melt-mixing and evaporation of the solvent.

The maxima of the peaks are associated with the polymer glass transition temperatures. As in other cases, DMTA $T_{\mathrm{g}}$ values are slightly 


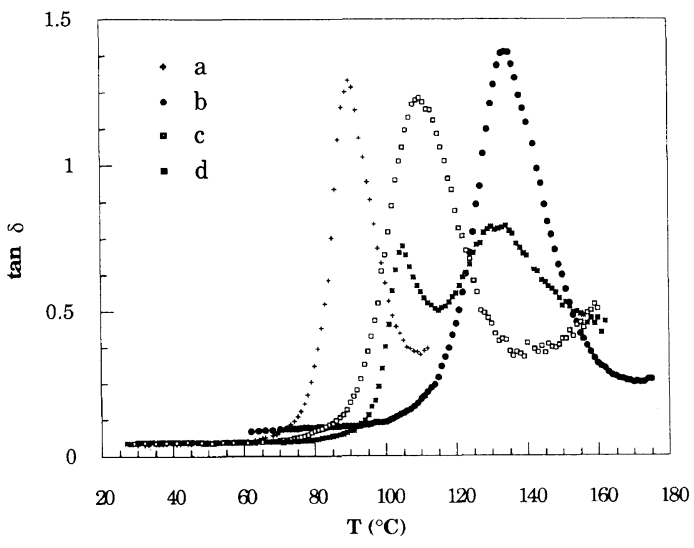

Figure 3. $\tan \delta$ versus temperature $\left({ }^{\circ} \mathrm{C}\right)$ plot for: a) pure PH, b) pure PMMA, c) PH/PMMA 50:50wt by melt-mixing, and d) PH/PMMA $50: 50$ wt by evaporation of the solvent.

different from those obtained by DSC experiments, given the different processes involved in the experimental determinations. In this case, maxima of the pure polymer peaks are sufficiently far appart to be well-defined in the case of an immiscible system. Melt-mixed blend shows only one peak intermediate to those of the pure components, as expected. However, two well resolved peaks are observed in the DMTA scan for the blend prepared by casting. These two maxima prove that, after casting, the blend is a two-phase system, probably due to the preferential solvent sorption of one of the components of the mixture.

\section{Solid-State ${ }^{13} C N M R$}

Solid-state CP-MAS ${ }^{13} \mathrm{C}$ NMR provides another approximation to the miscibility of a polymer blend. ${ }^{1-15}$ It also offers the possibility of proving blend miscibility in a much smaller dimensional scale than DSC or DMTA.

In general, resolution of the various polymer carbon signals in the NMR spectra of pure $\mathrm{PH}$ and blends was quite good, without significant problems related with the interference from spinning side bands. Measurements of the rotating frame spin-lattice relaxation times

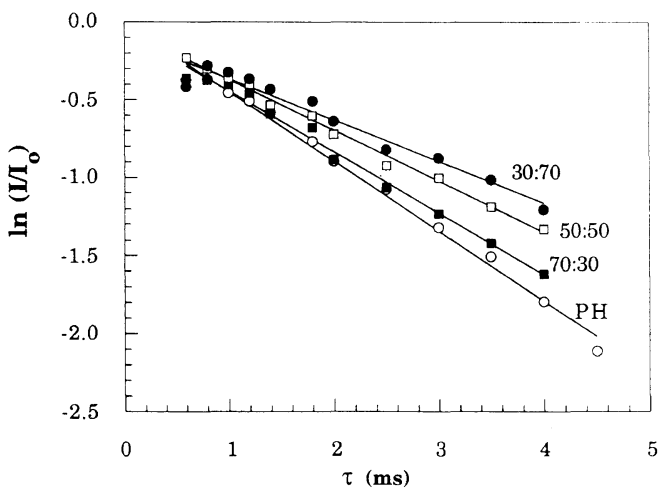

Figure 4. Plot of $\mathrm{PH}$ carbon magnetization at $157 \mathrm{ppm}$ against cross polarization contact time for pure $\mathrm{PH}, 70: 30$ PH/PMMA, 50:50 PH/PMMA, and 30:70 PH/PMMA.

$\left(T_{1 \rho}\right)$ were made by using a $90_{\mathrm{x}}^{\circ}-\tau$-spin lock pulse sequence, as mentioned above. The carbon signal intensity decay curves were fitted to a standard first-order kinetic expression

$$
I=I_{0} \cdot \exp \left(-\tau / T_{1 \rho}\right)
$$

which allows the determination of the relaxation times from a plot of the logarithm of the intensity ratio $\left(I / I_{0}\right)$ against the delay time $(\tau)$. From the slope the proton spin-lattice relaxation time in the rotating reference frame can be obtained. In general, relaxation times should be approximately independent of the carbon peak used to monitorize the signal decay. In our case, we have calculated relaxation times from the $\mathrm{PH}$ peaks at 127, 144, and $157 \mathrm{ppm}$.

Figure 4 shows the results obtained from the study at room temperature of the $\mathrm{PH}$ resin peak at $157 \mathrm{ppm}$ for pure $\mathrm{PH}$ and PH/PMMA $70: 30,50: 50$, and $30: 70$ blends prepared by precipitation.

For each blend, a single-component relaxation process was observed. Increasing the $\mathrm{PH}$ content resulted in shorter relaxation times, indicative of the efficient spin coupling on the time scale of the relaxation process. Relaxation times are summarized in Table III.

By determining the $T_{1 \rho}\left({ }^{1} \mathrm{H}\right)$ values for a blend in comparison to the $T_{1 \rho}\left({ }^{1} \mathrm{H}\right)$ values for 
Table III. Spin-lattice relaxation times (ms) of PH/PMMA blends at different PH carbon signals (ppm)

\begin{tabular}{cccc}
\hline \multirow{3}{*}{$\begin{array}{c}\text { PH/PMMA } \\
\text { composition }\end{array}$} & \multicolumn{3}{c}{$T_{1 \rho} / \mathrm{ms}$} \\
\cline { 2 - 4 } & $157 \mathrm{ppm}$ & $144 \mathrm{ppm}$ & $127 \mathrm{ppm}$ \\
\hline $100 / 0$ & 2.23 & 2.18 & 1.92 \\
$70 / 30$ & 2.82 & 2.52 & 2.31 \\
$50 / 50$ & 3.38 & 2.80 & 2.30 \\
$30 / 70$ & 3.84 & 2.54 & 3.44 \\
\hline
\end{tabular}

the pure polymers, it may be possible, under certain circumstances, to estimate an upper limit to the scale of heterogeneity present in the blend. ${ }^{11}$ If the scale of the phase separation in the blend is sufficiently small to permit rapid diffusion of the proton spin energy, a single-component relaxation process is observed and eq 6 may be used to estimate the upper limit to the domain size

$$
\left\langle L^{2}\right\rangle \cong\left(t / T_{2}\right)\left\langle l_{\mathrm{o}}^{2}\right\rangle
$$

where $l_{\mathrm{o}}$ is the distance between protons, $T_{2}$ is the proton spin-spin relaxation time, $t$ is the spin diffusion time constant set equal to the observed $T_{1 \rho}\left({ }^{1} \mathrm{H}\right)$ value, and $\left\langle L^{2}\right\rangle$ is the mean square distance over which magnetization is transported. Our data do not provide direct measurements of the spin diffusion coefficients but allow the application of eq 6 to estimate the upper limit to heterogeneity in the blends. For PH/PMMA, substituting in $t$ the highest value of $T_{1 \rho}\left({ }^{1} \mathrm{H}\right), 3.8 \mathrm{~ms}, T_{2}=10 \mu \mathrm{s}$, and $l_{\mathrm{o}}=0.1 \mathrm{~nm}$ yields an upper limit for mean diffusion distance $\langle L\rangle$ of approximately $1.9 \mathrm{~nm}$. The NMR results permit to conclude that the PH and PMMA blends are miscible in a comparable scale. The various protons in the blend are efficiently communicating spin energy on the time scale of the relaxation process.

\section{Viscosity Effects. Cloud Point Determination}

The previous results obtained with the blends prepared by casting made us think about the existence of a ternary diagram where blend phase separation occurs during the solvent evaporation. On trying to change the ternary diagram we prepared films in different ways: using the majority of the common solvents (THF, chloroform, dioxane, dimethylformamide, etc.), changing the evaporation temperature and evaporating the solvent under vacuum in a rotatory-evaporator or using an azeotropic mixture formed by acetone/chloroform 20:80 wt with an azeotropic point of $64.7^{\circ} \mathrm{C}$. Results were always the same: opaque films.

In order to get transparent films from casting, samples were heated on a hot plate stage up to $150-170^{\circ} \mathrm{C}$ for a large period of time. All the PH/PMMA films subjected to the treatment remained opaque. High polymer viscosity would not allow the subsequent remiscibilization of these two thermodynamically miscible polymers. In order to decrease polymer viscosity we also prepared many combinations of low molecular weight phenoxy resin and PMMA. These films were tested on a hot stage like previously. The immiscible (opaque) blend formed by very low molecular weight polymers (PH II and PMMA IV, with a molecular weight of 9300 and 9900 , respectively), only needed $30 \mathrm{~min}$ at $170^{\circ} \mathrm{C}$ to turn into transparent films. Transparency continued after cooling. The larger the molecular weight of the components the larger the time needed to get transparent films.

It can be concluded that these experiments support our hypothesis: opaque films do not become miscible when heating due to diffusion kinetic impediments related to polymer high viscosity. However, homogenization was possible with low molecular weight polymers because of the viscosity reduction.

Chiou and $\mathrm{Paul}^{9}$ have reported a LCST phase separation diagram for this blend. We have tried to confirm this cloud point curve diagram. An experimental cloud point curve can be obtained by heating a transparent film up to the first cloudiness is detected. In our 
case, samples were prepared by melt-mixing or coprecipitation, after which they were pressed under 10 tons at $180^{\circ} \mathrm{C}$. In these conditions transparent films were obtained. Two different experimental ways have been followed. Heating the film from room temperature to $300^{\circ} \mathrm{C}$ at a controlled rate, blends presented degradation evidences before reaching the phase separation temperature proposed by Chiou and Paul. ${ }^{9}$ Trying to avoid decomposition problems, the film was placed on the hot stage previously heated at a temperature close to the reported cloud point of the system. We were not able to confirm the phase separation behaviour of the system, even when raising the component molecular weights trying to make the LCST temperature value smaller and detectable. Blends formed by commercial $\mathrm{PH}$ and two high molecular weight PMMA were used: $\mathrm{PH} /$ PMMA II (50200) and PH/PMMA fr. (460000).

\section{Experiments with Tactic Polymers}

PH resin and s-PMMA presented very similar $T_{\mathrm{g}}$ values and therefore, the enthalpic relaxation method was also used as miscibility test. $\mathrm{PH} / \mathrm{s}$-PMMA results were similar to those of the PH/a-PMMA: one single enthalpy recovery peak when blends were prepared by coprecipitation or melting and two peaks when cast.

In the case of i-PMMA, $T_{\mathrm{g}}$ values were sufficiently far apart to be resolved in a classical DSC scan. No changes in the results were detected: one $T_{\mathrm{g}}$ when precipitated and two when cast. The evolution of the glass transition temperatures with the composition of $\mathrm{PH}$ blends with s-PMMA and i-PMMA are summarized in Figure 5.

Films of the phase separated samples prepared by casting were also subjected to heating processes. Transparent films were obtained from PH/s-PMMA blends heating the samples for a sufficient period of time $\left(185^{\circ} \mathrm{C}\right.$, $5 \mathrm{~h}) . \mathrm{PH} / \mathrm{i}$-PMMA blends became transparent in $30 \mathrm{~min}$ at $120^{\circ} \mathrm{C}$, a short period of time and

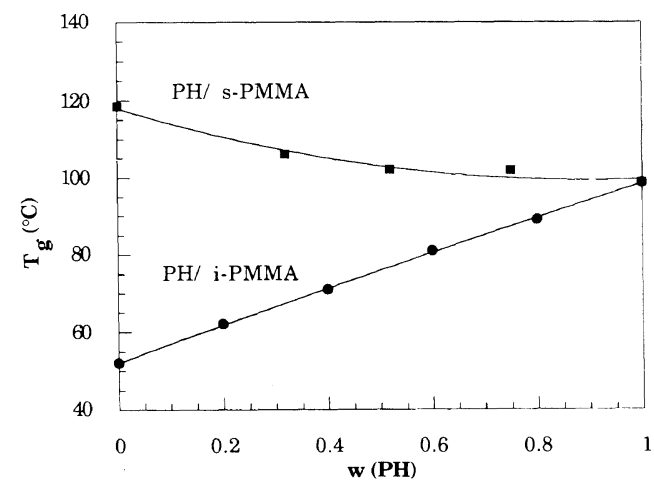

Figure 5. $T_{\mathrm{g}}$ vs. blend composition in blends of $\mathrm{PH}$ and s-PMMA and i-PMMA.

a low temperature if compared with the results obtained with atactic and syndiotactic PMMA. Transparency can be obtained with tactic polymers in all cases at an adecuate heating temperature in less than $5 \mathrm{~h}$. This is probably due to the low $T_{\mathrm{g}}$ of i-PMMA and the low molecular weights of the polymers we have used. It seems reasonable to conclude that in the investigated temperature range tacticity of PMMA has not any significant effect on its miscibility behaviour with $\mathrm{PH}$ resin.

Acknowledgments. This work has been supported by the University of the Basque Country (PIUPV 203215 E103/91) and by the Departamento de Economia (Diputacion de Guipuzcoa).

\section{REFERENCES}

1. L. M. Robeson, W. F. Hale, and C. N. Merriam, Macromolecules, 14, 1644 (1981).

2. M. Iriarte, J. I. Iribarren, A. Exteberria, and J. J. Iruin, Polymer, 30, 1160 (1989).

3. C. Uriarte, J. I. Eguiazabal, M. Llanos, J. I. Iribarren, and J. J. Iruin, Macromolecules, 24, 3038 (1987).

4. J. E. Harris, S. H. Goh, D. R. Paul, and J. W. Barlow, J. Appl. Polym. Sci., 27, 839 (1982).

5. E. Espí and J. J. Iruin, Macromolecules, 24, 6458 (1991).

6. H. Saito, D. Tsutsumi, and T. Inoue, Polym. Bull., 22, 128 (1990).

7. J. I. Eguiazabal, J. J. Iruin, M. Cortázar, and G. M. Guzmán, Makromol. Chem., 185, 1761 (1984). 
8. R. Erro, M. Gaztelumendi, and J. Nazabal, J. Appl. Polym. Sci., 45, 339 (1992).

9. J. S. Chiou and D. R. Paul, J. Appl. Polym. Sci., 42 279 (1991).

10. M. Bosma, G. ten Brinke, and T. Ellis, Macromolecules, 21, 1465 (1988).

11. J. F. Parmer, L. C. Dickinson, J. C. W. Chien, and R. S. Porter, Macromolecules, 22, 1078 (1989).

12. J. S. Schaefer, E. O. Stejskal, M. D. Sefcik, and R. A. McKay, Macromolecules, 14, 275 (1981).

13. J. S. Schaefer, E. O. Stejskal, and R. Buchdahl, Macromolecules, 10, 384 (1977).

14. X. Zhang, K. Takegoshi, and K. Hikichi, Macromolecules, 24, 5756 (1991).

15. J. F. Parmer, L. C. Dickinson, J. C. W. Chien, and R. S. Porter, Macromolecules, 20, 2308 (1987).

16. E. Lemieux and R. E. Prud'homme, Macromolecules, 21, 2148 (1988).

17. M. Kodama and K. Kuramoto, Polym. J., 22, 21 (1990).

18. E. J. Vorekamp, G. ten Brinke, T. G. Meijer, H. Jager, and G. Challa, Polymer, 26, 1725 (1985).

19. J. Brandrup and E. H. Immergut, Ed., "Polymer Handbook," 3rd ed, Wiley Interscience, New York, 1989.

20. J. I. Iribarren, M. Iriarte, M. Uriarte, and J. J. Iruin, J. Appl. Polym. Sci., 37, 3459 (1989).

21. R. Gooten and G. ten Brinke, Macromolecules, 22, 1761 (1989).

22. J. M. Cowie and R. Ferguson, Macromolecules, 22, 2313 (1989).

23. T. S. Ellis, Macromolcules, 23, 1493 (1990).

24. J. M. Hodge and A. R. Berens, Macromolecules, 15, 762 (1982)
25. R. W. Rendell, T. K. Lee, and K. L. Ngai, Polym. Eng. Sci., 24, 1104 (1984).

26. S. C. Jain and R. Simha, Macromolecules, 15, 1522 (1982).

27. A. J. Kovacs, J. J. Aklonis, J. H. Hutchinson, and A. R. Ramos, J. Polym. Sci., Polym. Phys. Ed., 17, 1097 (1979).

28. M. R. Tant and G. L. Wilkes, Polym. Eng. Sci., 21, 874 (1981).

29. J. M. G. Cowie and R. Ferguson, Polym. Commun., 27, 258 (1986).

30. H. Yoshida and Y. Kobayashi, J. Macromol. Sci., Phys. Ed., B21, 565 (1982).

31. H. Yoshida, K. Nakamura, and Y. Kobayashi, Polym. J., 14, 865 (1982).

32. H. Yoshida and K. Kobayashi, Polym. Eng. Sci., 23, 907 (1983).

33. A. R. Berens and J. M. Hodges, Macromolecules, 15, 756 (1982).

34. J. M. Hodges and G. S. Huvard, Macromolecules, 16, 371 (1983).

35. J. M. Hodge, Macromolecules, 16, 898 (1983).

36. J. M. Hodge and A. R. Berens, Macromolecules, 18, 1980 (1985).

37. J. M. G. Cowie, S. Elliot, R. Ferguson, and R. Simha, Polym. Commun., 28, 298 (1987).

38. C. T. Moyhigan, A. T. Bruce, D. L. Gavin, S. R. Loehr, and S. M. Opalka, Polym. Eng. Sci., 24, 1117 (1984).

39. H. Yoshida, H. Kanbara, N. Takemura, and Y. Kobayashi, Sen'i Gakkaishi, 39, 1512 (1983).

40. O. S. Narayanaswamy, J. Am. Ceram. Soc., 54, 491 (1971).

41. A. Q. Tool, J. Am. Ceram. Soc., 29, 240 (1946). 